12th LUMEN International Scientific Conference Rethinking Social Action. Core Values in Practice | RSACVP 2019 | 15-17 May 2019 | lasi - Romania

\title{
Initial Construction and Validation of Parental Role Assuming Scale (PRA)
}

\author{
Maria-Laura HOREANU \\ https://doi.org/10.18662/lumproc. 161
}

How to cite: Horeanu, M.-L. (2019). Initial Construction and Validation of Parental Role Assuming Scale (PRA). In C. Ignatescu (ed.), 12th LUMEN International Scientific Conference Rethinking Social Action. Core Values in Practice, 15-17 May 2019, Iasi Romania (pp. 141-151). Iasi, Romania: LUMEN Proceedings. https://doi.org/10.18662/lumproc.161 



\title{
Initial Construction and Validation of Parental Role Assuming Scale (PRA)
}

\author{
Maria-Laura HOREANU ${ }^{1}$
}

Abstract

Parenthood is often viewed as a period with more changes in mother's life than fathers in terms of cultural aspects and society's assumption that mothers are the main sources of child care. At the same time, the roles of the family and the relationships between parteners have changed in Western societies, compared to the traditional model, in which father is being more involved in caring and educating children.

Most of the studies that have been done, have construct, validated and/or used tools that measure the relationship between parent and child, but the approach to parental assuming, especially in the context of childbirth, has been neglected. The need to construct this instrument has come from the intention to analyze the extent to which the assuming of the parental role during the transition to parenthood influences marital satisfaction. So, in this study we constructed and validated the Parental Role Assuming (PRA) tool. Exploratory factorial analysis was performed to identify the parental component's factorial structure by using component analysis and varimax rotation. A structure of the construct tool model indicates three factors for the 13 items with a percentage of 59.49 of the total item variance.

The validity of the convergent construct was obtained by significant correlations of the scale with the close items of the PCRI instrument [6]. Regarding the fidelity of the instrument, we obtained a total alpha cronbach of 0.81 , and for the three subscale the internal consistency ranged from 0.80 to 0.70 .

Keywords: parenthood; transition to parenthood; assuming parental roles; marital satisfaction; measurements.

\section{Introduction}

The moment of a child birth represents for most parents and families an important and joyful event, and when the first child is born, we

\footnotetext{
${ }^{1}$ PhD Student, Iaşi, România, smilschi.laura@yahoo.com. 
can talk about a new family life, characterized by the transition from partner to parent.

The new role requires parents certain behavioral that usually were not part of the usual habits, including the adaptation strategies that lead to new life patterns. Oftentimes awaited the child birth produces changes that modify for always the role of both parents and the whole family. They are gradually entering a trial of modification that needs a period to readapt. Over this time, the child enter gradually in the family climate and the relationships between the other members are redefined. [11].

Historically speaking, family roles and interactions between partners have changed in occidental societies, from the traditional model in which the whole family responsibility came to the man model to the postmodern ones, with a new family typology. The father's role is no longer regarded as the supporter, but also involves a greater affective connection with the children. Some studies show that the paternity separation line from maternity begins to fade, indicating less participation of men in child care, and other longterm studies have indicated an enlargment in gender gaps over and after the parental transition. For example, in 2010, Katz-Wise in a longitudinal study of 205 couples to the first child and 198 couples to the second child shows that parents have generally become more traditional in terms of attitudes and sex behaviors after the child birth, women report more changes than men, and parents who were at the first child experience have changed more than their second-born parents [8]. Modern paternity requires not only the adoption of maternal practices, but also emphasizes the importance of expressing warmth and emotion, suggesting protection, care and interest in the health and development of the child in general.

Father's involvement in educating children raises a burden on the wives and mothers whose life satisfaction increases significantly by reducing household duties and responsibilities in general [13]. Another study by Krimberg in 2012 [10] emphasizes the paternal role in the child's life, and highlights that in recent years men have been more interacting with family members, especially children, and enjoyed more family life than previous decades. For Krimberg, the concept of paternity involves a process of social experience of paternity through the construction of emotional bonds and goes beyond the naturalistic and biological vision that justifies the relationship established between father and son/daughter [10].

There are studies that associate the transition to parenthood with great difficulties in couples where partners tend to adopt the traditional style of shared responsibilities after birth, the problems between parteners tend to increase, parents reporting lower levels of marital satisfaction, significantly higher pressure and the lifestyle begins to have many modifications for both 
partners [12]. Thus, parents have a new identity and redistribute their attention to other roles. There are a number of prenatal factors that help family recovery and conjugal satisfaction such as family experience in housework, household and child care expectations, and friends and family help [12].

Most studies show that being a parent is most frequently related with more changes in mother's life than fathers, if we take in consideration the cultural aspects and the widespread assumption that mothers are the main sources of child care. Besides family-specific tasks, parents and mothers interact differently with their children. As a result, even though they are unconscious, mothers seem to adopt behaviors compatible with an intensive care program to limit parental involvement in parental tasks, offering the expected high level of performance [11].

The transition to parenthood determines the distribution of new roles that can strengthen the couple's relationship. A factor that has been identified and found to have an influence on the emotional state of parents is the congruence of parental roles. The parental congruence refers to the commitment that each partner assumes as regards parental roles in the family [1].

The results of the longitudinal study carried out by Cowan and conducted on a number of forty-seven couples who were parents for the first time evaluated during the last trimester of pregnancy and again at 6 and 18 months postpartum show that generally, couples who agree with roles that have returned, experience lower changes in well-being [3]. It has also been found that spouses disagreements on role distribution can be associated with a high stress level and a dissatisfaction in the couple's relationship due to differences of values in general. The relationship between roles, individuals, and marital status should be higher when individuals become parents and begin to verify their parental identity [3].

\section{Problem Statement}

The concept of assuming the parental role was proposed in the parental autoregulatory theory developed by Sanders in 2008 [18]. In turn, it involves the concepts of self-regulation and self-orientation, constructs incorporated into a series of psychological theories and considering these processes as being malleable and sensitive to intervention. This psychological concept is relevant not only for the understanding of parents' pliability and confidence, but is also useful in the further anticipation of the relationship between parent and child [7]. 
Another important theory is the maternal role acquisition, developed by Rubin in 1984 in Maternal identity and maternal experience, and which was introduced as a process that leads to the realization of a maternal identity [17]. Rubin enumerates and analyzes the "progressive stages of the process" that begins during pregnancy, such as „imitation”, ,role play”, „fantasy”, ,internalization-projection-rejection”, and „identity” [17]. For Rubin, maternal identity is a final point in assuming the maternal role, having understood the role it plays, along with a sense of reconciliation on its past and future [17]. Personal or maternal identity is seen as a feeling of stability, trust, accomplishment in the maternal role and affection to one's own child [14].

According to Coroban, the parental role describes the relationship between child-parents with emotional, education, and kinship particularities [2]. At the same time, the author emphasizes that assuming the parental role begins with the assuming the responsibilities, namely the stage of raising and educating children, evolving to the formation of the sexual identity of children and continuing by stimulating evolution and personality development in descendants [2].

According to the development stages described by Erikson (1959), the period of parenthood is between 35 and 65 years [4]. This period is characterized by the need for the adult to be productive, to be able to relate himself towards his/her exteriors and to exercise his or her parenting role.

The concept of role has been defined from two theoretical perspectives. From structuralist model perspective, the role is defined as status or as the total amount of cultural patterns. In the interactionist tradition, roles are seen as the results of social interactions [19].

Regarding parental roles, a study in 1976 by Gecas show that $62 \%$ of spouses and $42 \%$ of spouses responded that they should have equal responsibilities in raising children [5]. But when it came to specific tasks, it was found that wives must be responsible for the food, cleanliness and satisfaction of children's affective needs, while men must provide child safety and protection.

The roles assumed by parents are those that influence the family atmosphere, this being the one that has a direct effect on the development of the child and the adult later. The problem of adopting an appropriate family role raises difficulties even in the case of couples with high personality compatibility in all areas.According to family systems theory, relationships changes over time and are affected by changes in family life [9].

Research that examined the link between the quality of marital relationships and parental characteristics shows that high marital satisfaction 
and low conjugal conflicts are associated with a positive parental role among parents who have small children.

From a family systems theory perspective, marital processes and parental roles are not static, but are expected to change over time in the context of certain family circumstances. The domain of family systems was also studied by Mitrofan (1998), which brings to attention the structural theory that suggests the issue of changes that can occur within a couple [15]. Thus, the differences between the family structure of the traditional family and the family of the modern type have been discussed, and in this context the importance of assuming the role of each partner in the couple after the birth of the child is emphasized. At the same time, the structure of marital roles is also influenced by certain factors such as: partner level of education, socio-professional category, relations established outside the conjugal nucleus, etc. [15]. Most of the time, the birth of a child represents fulfillment and joy, and being a parent has many gainings such as affection, a sense of personal self-satisfaction, fulfillment of needs, social expectations and relational balance. Moreover, is necessary adapt to the new role in the parental position, which constantly takes care and attention. Overcoming episodes of crying, physical demands for baby feed, and less rest especially at night represents something new, parents have to deal with. When a child is born, parents feel happiness, fulfillment and have a plenty of soul gains, such as love, self-fulfillment, fulfillment needs, social expectations and relational stability. However, the birth of a child is also a challenge for the family. Partners need to adapt to their new parenting role, which they must pay attention to and importance. When they become parents, partners have to deal with complaints of crying, physical demands for breastfeeding and sleep disorders, all of which add to the natural challenges of couples when they become parents. Concentration of self-directed attention and self-directed energy goes towards the child, and this can have a negative effect on marital satisfaction [9].

\section{Aims of the research}

The purpose of the study is to validate a tool built and adapted after the „Parent Child Relationship Inventory” (PCRI, [6]) to measure concept of parenting. To build and validate the tool, I started from the PCRI questionnaire.

PCRI is a tool that includes 78 items that measure parenting skills and attitudes toward parenting and children in general. The instrument includes 7 subscale: 1. „Parent support”, 2. „Satisfaction with parenting”, 3. 
„Involvment”, 4. „Communication”, 5. „Limit setting” 6. „Autonomy” 7. „Role orientation” [6]. In addition, PCRI includes two indicators of validity: „Social Desirability Scale”, which indicates whether the subject was honest when responding, and Internal Consistency Indicator indicating whether the subject responded accidentally or inadvertently. The internal consistency is good, with an alpha cronbach coefficient of 0.82 . The authenticity of the data has been demonstrated by the test-retest procedure to obtain similar responses resulting in a coefficient of 0.81 . From the seven subscales of the instrument, we selected and reformulated 6 items from the subscale of satisfaction with the parental role and 3 items from parental involvement. We also built another five items to measure the concept we want to evaluate. Finally, the instrument under validation comprises 14 items, of which five are reversed.

\section{Research Methods}

\section{Participants}

The study was attended by 210 mothers, married or in a relationship, between 25-43 year-old from urban and rural environment. The group of subjects was selected from the maternity, as well as from the kindergartens and schools in Iasi.

\section{Description of the scale}

The scale was built to measure the parental role starting from the parental development theory (PRDT) developed by Respler \& Mowder [16] and the maternal role theory developed by Rubin [17].

Building this scale was necessary to analyze the extent to which assuming a parental role in the period of becoming a parent influences marital satisfaction. In this period, partners are adapting to their new roles. Studies in this field show that a poor or a lack of parental involvement can affect the couple's relationship but also the relationship with the children and the negotiation of parental roles in the couple. It is particularly important on the one hand to draw from the beginning the responsibilities of each other and on the other hand to avoid conflicts and to create a balance in the family in general.

The importance of building and validating parenting is its ability to measure the degree of partner adaptation to new roles of parents. Also, the 
lack of an instrument to measure this psychological construct in the period of becoming a parent in European space gives PRA scale originality.

The theory of parental development emphasizes how parents perceptions about parental roles changes over time and how this influence the parent-child relationship, family dynamics, as well as the socio-cultural environment.

The maternal role theory developed by [17] Rubin has been introduced as a process that leads to the realization of a woman's maternal identity. [17] Rubin describe „maternal identity as a final point in assuming the maternal role, as having a meaning in the role it occupies along with a sense of comfort over its past and future" [17]. The period of ,,personal” or „maternal identity” is seen as a feeling of wellbeing, trust, fulfillment in the mother role and affection to one's own child [14].

Thus, we extracted three of the most common dimensions of „parental assuming”, namely „parental satisfaction”, „parental involvement” and ,assuming parental decision". After analyzing the theoretical model, we built a tool with 14 items. Starting with the PCRI instrument [6], we selected and reformulated 6 items from the subscale of parental satisfaction and 3 items from parental involvement. We also built five other items to measure the concept we want to evaluate. The instrument build-up was done through exploratory factorial analysis using main components analysis and varimax rotation. The convergent validity analysis was achieved by the correlations obtained between total score of PRA instrument and total score of the close items as meaning of the PCRI scale. Finally, the instrument under validation comprises 13 items, of which five are reversed $(2,3,5,8,9)$.

\section{Procedure}

Subjects had the task of answering 14 items on a Likert-type scale where one represents a strong agreement, two-agreement, threedisagreement, and four-strong disagreement. Each participant was trained on how to complete the scale to prevent any misunderstandings. It has also been explained that the results of the instrument will be used for research purposes and data is confidential.

\section{Findings}

\section{Construct validity}




\section{Exploratory factorial analysis}

Exploratory factorial analysis was performed to identify the parental component's factorial structure by using component analysis and varimax rotation. To verify that there are sufficient correlations between items, we used the Kaiser-Meyer-Olkin value and the Barlett spherical test. The KMO and Barlett test scores were equal to .802 and $1028.56(\mathrm{p}<.0 .001)$ respectively.

These results indicate the data match for an exploratory analysis. These data also suggest that the items are close to the factorial model. Both the Kaiser criterion (eigenvalue greater than 1) and the Catell graph indicate three factors as a solution for the 13 items. For the three factors, the following values were obtained: $37,12,12,32$ and 12,74 , and the total factors obtained 59.49 of the total item variance. The final form of the scale containing 13 items is the following: parental involvement-5 items $(6,10,11,12,13)$, parental satisfaction-5 items $(1,3,4,5,14)$, assuming the decision to be parent-3 items $(2,8,9)$.

Table no.1 - Factor loadings following (rotated) exploratory factor analysis

\section{Items}

I.11. I am involved a lot in my childs care.

\begin{tabular}{|c|c|}
\hline & FACTORS \\
\hline & $\begin{array}{lll}1 . & 2 . & 3 . \\
.78 & & \end{array}$ \\
\hline wth become a priority & .75 \\
\hline
\end{tabular}
for me.

I.10. I spend a lot of time with my child.

I.13. I am a parent involved in all aspects of my child care.

I.6. Being a parent is very important for me.

I.5. I often feel overwhelmed by my responsibilities as a parent.

I.14. The transition from the role of wife at the role of parent occurred naturally for me.

I.3.Is not very satisfying to be a parent.

I.4. Generally,I feel good in the role of parent.

I.1. I think I have the qualities to be a good parent.

I.8. I would prefer to do a lot of other things than spending time with my child.

I.9. If I were to give time back, I probably would not have children.

I.2. I regret the decision to have a child.

„Extraction Method: Principal Component Analysis. Rotation Method:Varimax with Kaiser Normalization". 


\section{Convergence Validity}

Convergence validity scale was obtained through the correlations of the total score of the parental instrument with the total score of the items adapted to the PCRI questionnaire, namely item $(2,3,6,8,9)$. Parental role assumptions and Parental Child Relationship (PRI) correlations are significant and positive $(\mathrm{R}=.92, \mathrm{p}<0.001)$. The correlation coefficient reveals that the proposed validation tool correlates significantly with the nearby items of the PCRI tool, resulting a strong and significant link and a convergent construct validity.

\section{Fidelity}

To determine the internal consistency of the PRA tool we used alpha cronbach. This coefficient is recommended for multiple-response tools. For total alpha cronbach we obtained 0.81 . For the three subscales, the internal consistency was the following: Parent Involvement-0.80, Parent Satisfaction0.73, Assuming the parental decision-0.55. Because we have obtained a low internal consistency score on the subset of assuming the parental decision, we chose to remove item 7 using item-total statistics (Cronbach Alpha if item deleted). After we removed item 7 , the alpha value increased to 0.70 . Thus, the final version of the PRA tool includes 13 items.

\section{Discussions}

This study describes the construction and initial validation of the Parent Role Assuming (PRA) instrument. The construct analysis was performed using exploratory factorial analysis using main components analysis and varimax rotation through which three factors were identified for the 13 items with a 59.49 of the total variance of items.

There are many positive aspects regarding the design and methodological approach of our study. We obtained different subcategories of construct validity and a good internal consistency score, both total and subscales. The scale is easy to use with few items and good psychometric properties. From a theoretical point of view, the scale can also be used for research purposes on other target groups. From a practical point of view, the instrument can be applied for clinical or therapeutic purposes to measure the 
level of assumption of the parental role in the family. The study also contains a number of limitations including the lack of fidelity obtained by the test-retest, the participation in the study were only women and not also men. The version proposed in this study should also be applied to men. In the future explorations and examination of the psychometric properties of the scale, it is necessary to analyze the divergent validity and test- retest fidelity.

\section{Conclusions}

Starting from the parental development theory, maternal role theory and the Parent Child Relationship Index we built a 13-item scale that measures the parental role assuming. The need to build parental role assuming scale (PRA) has been particularly important for several reasons. From a methodological point of view, the need to construct and validate such an instrument comes from the lack of another scale to measure this psychological construct. From a practical point of view, the tool is addressed to new parents, but also specialists working in the field of couple and family. Based on the exploratory analysis, we concluded that there are three dimensions of assuming the parental role, namely parental involvement, parental satisfaction and assuming the decision to be a parent. In this preliminary study, we have established a version of the 13-item tool. A high score obtained at the PRA scale indicates an increased level of assuming a parental role. Our preliminary study suggests that PRA can ensure a valid and accurate measurement of parental assuming role. However, it is necessary to provide new evidence and arguments for the validity and fidelity of the PRA tool test-retest.

\section{References}

[1] Cast AD. Well-Being and the Transition to Parenthood: An Identity Theory Approach. Sociological Perspectives. 2004;47(1):55-59.

[2] Coroban C. Raporturi sociale în sistemul familial Universitatea de Stat din Moldova. Revista Ştiințifică a Universităţii de Stat din Moldova. 2013;8(68):1617.

[3] Cowan CP, Cowan PA. Who Does What When Partners Become Parents: Implications for Men, Women, and Marriage. Marriage \& Family Review. 1988;12(3-4):105-3.

[4] Erikson EH. Identity and the life cycle: Selected papers. Psychological Issues. 1959; 1:1-171. 
[5] Gecas V. The socialization and Child Care Roles, Role Structure and Analysis of the Family. London: Sage Publications; 1976.

[6] Gerard AB. Parent-child relationship inventory (PCRI). Los Angeles, Calif: Western Psychological Services; 1994. p. 1-3.

[7] Hamilton VE, Jan MM, Crawford SB. Development and Preliminary Validation of a Parenting Self-Regulation Scale: "Me as a Parent", New York: Springer Science+Business Media; 2014. p. 2853-2855.

[8] Katz-Wise SL, Priess HA, Hyde JS. Gender-role attitudes and behavior across the transition to parenthood. Developmental Psychology. 2010;46(1):18-28.

[9] Kluwer ES. From Partnership to Parenthood: A Review of Marital Change Across the Transition to Parenthood, Utrecht University. Journal of Family Theory and Review. 2010;105-121.

[10] Krimberg von Muhlen B, Saldanha M, Strey MN. Mothering fathers: changes in sight?, Brasil: Pontifícia Universidade Católica do Rio Grande do Sul; 2012. p.9-12.

[11] Martins CA, Pinto de Abreu WJC, Barbieri de Figueiredo MCA. Becoming a father and a mother: a socially constructed role. Research Paper. 2014; 121 130.

[12] Martins CA. (2009). Transition to parenting: A systematic review of the literature. In MC Barbieri, MM Martins, MH Figueiredo, MJ Martinho, LM Andrade, PC Oliveira, MR Santos, editors. From research to family nursing practice. Porto, Portugal: Porto Nursing School, p. 115-127.

[13] Maskalan A. In the Name of the Father: A Discussion on (New) Fatherhood, Its Assumptions and Obstacles. Institute for Social Research. 2015;383-392.

[14] Mercer RT. Becoming a Mother Versus Maternal Role Attainment. Journal of Nursing Scholarship. 2004; 226-229.

[15] Mitrofan I, Ciupercă C. Incursiune în psihosociologia şi psihosexologia familiei. Bucureşti: Editura Press; 1998. p. 143-163.

[16] Respler-Herman M, Mowder BA. Parenting Beliefs, Parental Stress, and Social Support Relationships. J Child Fam Stud. 2012;21:190-198.

[17] Rubin R. Maternal identity and the maternal experience. American Journal of Nursing. 1984;84(12):1480-1482.

[18] Sanders MR. Triple P-Positive Parenting Program as a public health approach to strengthening parenting. Journal of Family Psychology. 2008;22(4):506-517.

[19] Solomon MR. The Role of Products as Social Stimuli: A Symbolic Interactionism Perspective. Journal of Consumer Research. 1983;10(3):319_ 329. 